\title{
Vroeë woordelyste en woordeboeke in verband met Afrikaans ${ }^{1}$
}

\author{
W. Gericke, Buro van die Woordeboek van die Afrikaanse Taal
}

\begin{abstract}
Early Word-lists and Dictionaries in Connection with Afrikaans. The beginning of professional lexicography in South Africa can be taken as far back as 1926, when Prof J.J. Smith officially started the work on Die Afrikaanse Woordeboek (later also known as the Woordeboek oan die Afrikeanse Taal). This article considers the state of Afrikaans lexicography at that time and takes a view of the Afrikaans and pre-Afrikaans word-lists and dictionaries published before 1926. Publications between 1844 and 1925 are discussed. Some of the early pioneers in lexicography were the Dutch who had settled in South Africa and whose contribution still had a strong Dutch character. Only as a result of the influence of the so-called Tweede Afrikaanse Taalbeweging after 1905 and the work of the Zuid-Afrikaanse Akademie voor Taal, Letteren en Kunst that was founded in 1909, Afrikaans lexicographic publications were less influenced by this Dutch element. By 1926 the foundation of a lexicographic tradition had been established. Afrikaans explanatory lexicography was, however, still an unknown and unexplored field.
\end{abstract}

Keywords: AFRIKAANS, EARLY WORD-LISTS AND DICTIONARIES, PROFESSIONAL LEXICOGRAPHY

Opsomming: Die begin van die professionele leksikografie in Suid-Afrika kan teruggevoer word na 1926 toe prof. J.J. Smith amptelik met die werk aan Die Afrikaanse Woordeboek (later ook bekend as die Woordeboek van die Afrikaanse Taal) begin het. In hierdie artikel word daar ingegaan op die stand van die Afrikaanse leksikografie teen daardie tyd en op die Afrikaanse en voor-Afrikaanse woordelyste en woordeboeke wat voor 1926 verskyn het. Werke wat van 1844 tot 1925 gepubliseer is, word bespreek. Van die vroeë leksikografiese baanbrekers was Nederlanders wat hulle in Suid-Afrika gevestig het. Hulle werk het nog 'n sterk Nederlandse karakter gehad. Eers deur die invloed van die sogenaamde Tweede Afrikaanse Taalbeweging ná 1905 en die werk van die ZuidAfrikaanse Akademie voor Taal, Letteren en Kunst wat in 1909 tot stand gekom het, is die Afrikaanse leksikografiese produkte in 'n groot mate van hierdie Nederlandse inslag gesuiwer. Teen 1926 was die grondslag van 'n leksikografiese tradisie in Suid-Afrika gelê, maar die Afrikaanse verkJarende leksikogr afie was nog 'n onbekende en onverkende terrein.

Sleutelwoorde: AFRIKAANS, VROEë WOORDELYSTE EN WOORDEBOEKE, PROFESSIONELE LEKSIKOGRAFIE

Hierdie artikel is 'n gedeelte van 'n hoofstuk, met enkele aanpassings, uit 'n M.A.-skripsie Die Woordeboek oan die Afrikeanse Taal - 'n kultuurhistoriese verkenning wat in Maart 1991 deur die Universiteit van Stellenbosch aanvaar is. 


\section{Drie Nederlandse baanbrekers}

Toe prof. J.J. Smith in 1926 amptelik met die werk aan Die Afrikaanse Woordeboek (later ook bekend as die Woordeboek van die Afrikaanse Taal) begin het, was dit die begin van die professionele leksikografie in Suid-Afrika. In hierdie artikel word daar ingegaan op die stand van die leksikografie teen daardie tyd en die Afrikaanse en voor-Afrikaanse woordelyste en woordeboeke wat voor 1926 verskyn het, word bespreek.

Die eerste optekeninge van Afrikaans is nie deur Afrikaners gedoen nie, maar deur Europese reisigers en Nederlanders wat hulle in Suid-Afrika gevestig het. In die neëntiende eeu en selfs daarna is Afrikaans as die veragte "kombuistaal" nie eers deur die sprekers daarvan gereken teenoor die deftige Nederlands en die wêreldtaal Engels nie. Die sprekers van Afrikaans het nie die waarde van die eie taal raakgesien nie en dit het nooit by hulle opgekom om die taal op te teken nie. Enkele persone met 'n Europese kultuuragtergrond wat 'n kennis gehad het van Europese streektale, het die verskille tussen Afrikaans en Nederlands opgemerk en dit begin bestudeer (Snijman 1975: 2).

'n Voorloper in dié verband was Antoine Nicolas Ernest Changuion (1803-1881), 'n Nederlander van Hugenote-afstamming wat in 1831 as professor in die klassieke en moderne tale, veral Nederlands, aangestel is aan die pas gestigte Zuid-Afrikaansche Athenaeum, waaruit later die Universiteit van Kaapstad ontstaan het. Dit was 'n tydperk van verengelsing aan die Kaap en Changuion het hom daarop toegelê om die Nederlandse taalbelange te bevorder. Teen hierdie agtergrond het daar in 1844 'n werk van hom verskyn: $D e$ Nederduitsche taal in Zuid-Afrika hersteld, zijnde eene handleiding tot de kennis dier taal naar de plaatselijke behoefte van het land gewijzigd. Agterin het dit ' $\mathrm{n}$ "toegift" bevat van ongeveer 20 bladsye met omtrent 400 Afrikaanse woorde en wendinge met grammatiese aantekeninge onder die opskrif "Proeve van Kaapsch taaleigen" (Nienaber 1950: 17-20; Snijman 1975: 2-3).

Eers veertig jaar later, in 1884, het daar weer 'n boek met Afrikaanse woordmateriaal verskyn. Dit was die Proeve van een Kaapsch-Hollandsch idioticon, met toelichtingen en opmerkingen betreffende land, volk en taal van Nicolaas Mansvelt (1852-1933). Mansvelt was 'n Nederlander wat in 1874 as dosent in moderne tale aan die Stellenbosch College aangestel is. In sy Idioticon behandel hy ongeveer 2000 woorde met toeligtende aantekeninge in Nederlands. Later, toe hy Superintendent-generaal van Onderwys van die Zuid-Afrikaansche Republiek was en ook ná sy terugkeer na Nederland, was hy Suid-Afrika se skakel met die Woordenboek der Nederlandsche Taal (WNT), waarvan die eerste aflewering in 1864 verskyn het (Boshoff 1926: 311-312; Mansvelt 1884: i; Snijman 1975: 3).

In 1926 skryf S.P.E. Boshoff (1926: 312) in 'n belangrike artikel oor "'n Standaard woordeboek van Afrikaans": "Mansvelt se Idioticon [vorm], ten spyte van sy flagrante flaters en studentefiksie, vandag nog een van die hoekstene van ons Afrikaanse leksikografie." Dit is belangrik om in gedagte te hou dat in 
hierdie werk, net soos in die Proeve van Changuion, Afrikaans gesien is uit die gesigspunt van Nederlands, wat die amptelike taal van die twee Boererepublieke was en van 1882 ook in die Kaapse Parlement as amptelike taal naas Engels erken is (Snijman 1975: 4).

Sedert die tyd van Changuion was daar egter ' $n$ groter bewuswording van die Afrikaanse taal en die man van wie 'n buitengewone invloed in dié verband uitgegaan het, was nog ' $n$ Nederlander, Amoldus Pannevis (1838-1884). Pannevis was eers skeepsdokter, maar het daarna in die lettere gestudeer en kort na die aflegging van sy kandidaatseksamen na Suid-Afrika gekom waar hy in 1866 as onderwyser in die klassieke tale aan die Paarl Gymnasium aangestel is (Snijman 1975: 4-5). Volgens ds. S.J. du Toit, een van sy leerlinge en later leier van die Eerste Afrikaanse Taalbeweging, was hy "werkelik die eerste [wat] met erns die gedagte uitgespreek het en ons o'ertuig het, dat ons 'n eie taal het, en wel 'n voortreflike taal, wat ons moet erken en beoefen" (Pienaar 1946: 88-89).

Op 4 November 1874 het daar 'n stuk, waarskynlik van Pannevis, in die Kaapse blad De Zuid-Afrikaan verskyn oor die vraag: "Is die Afferkaans wesenlijk een taal?" Daarin propageer hy die totstandkoming van "Un genootskap foor die befordering fan die Afferkaanse taal". Hy het dit bepleit dat die genootskap ' $n$ boekie met Afrikaanse taalreëls moet uitgee met die titel Eerste beginsels fan die Afferkaanse spraakkennis. Dit moet dan dadelik opgevolg word met Een Afferkaans woordeboek. Hy vervolg: "In die twee boeken sal iedereen wat niet blind is nie dan'wel sien, dat ons Afferkaans wel wesenlyk een taal is; een taal wat door iedereen kan gespreek word, door die Engelsman self" (Scholtz 1939: 241; Snijman 1975:5).

\section{Tydperk van die Eerste Afrikaanse Taalbeweging en die Tweede Vry- heidsoorlog}

Die Eerste Afrikaanse Taalbeweging is ingelui deur die stigting van die Genootskap van Regte Afrikaners (GRA) in 1875 onder leiding van S.J. du Toit. In 1876 is die Eerste beginsels van die Afrikaanse taal gepubliseer. In 1902 is die tydperk van die GRA afgesluit met die publikasie van die eerste Afrikaanse woordeboek: die tweetalige Patriot woordeboek/Patriot dictionary. Pannevis het nie self aktief meegewerk aan hierdie woordeboek nie; hy is in 1884 oorlede. Hy het egter 'n uitvoerige lys van Afrikaanse woorde met aantekeninge opgestel wat na sy dood deur S.J. du Toit onder sy geskrifte gevind en deur hom vir die Patriot woordeboek gebruik is. 'n Afskrif van die Pannevis-lys, gemaak deur J.J. Smith, is later deur H.J.J.M. van der Merwe in sy Vroë̈ Afrikaanse woordelyste opgeneem (Snijman 1975: 5-6).2 
In 1879 het ' $n$ boek van T.M. Tromp in Leiden verskyn met die titel Herinneringen uit Zuid-Afrika ten tijde der annexatie van de Transvaal. Weinig is omtrent Tromp bekend, maar hy was 'n Nederlander en sekretaris van pres. T.F. Burgers en het nie lank in Suid-Afrika vertoef nie. Hoofstuk 22 van sy boek handel oor "De Afrikaansche taal" waarvan hy maar 'n lae dunk het: "De Afrikaansche taal, die tot stam de Oud-Hollandsche taal heeft, is zeker wel het leelijkste en meest vermengde dialect, dat ooit bestond" (Van der Merwe 1971: ix-xi, 19). In hierdie hoofstuk is 'n lysie "van de gebruikelijkste en eigenaardigste woorden en uitdrukkingen" (Van der Merwe 1971: 26) wat heelwat foute en skewe voorstellings bevat, maar wat tog van belang is omdat dit die eerste woordelysie was wat uit die Transvaal afkomstig was (1971: xi). H.J.J.M. van der Merwe het dié lysie in sy Vroeë Afrikaanse woordelyste opgeneem.

'n Woordelysie wat veral bestaan het uit Oosterse woorde wat aan die Kaap voortgeleef het, het in 1882 verskyn. Die opsteller was H.C.V. Leibbrandt (1837-1911) van Kaapstad wat in Nederland in die teologie gestudeer het. Hy het later die bediening verlaat en in 1881 die eerste argivaris van die Kaapprovinsie geword. In sy woordelysie gee Leibbrandt interessante woordafleidings wat egter nie altyd bo verdenking is nie. Die lys verskyn ook in Vroeë Afrikaanse woordelyste (Van der Merwe 1971: xi).

In 1885 (tweede uitgawe 1887) verskyn by D.F. du Toit en Co. in die Paarl 'n werkie van J.W. van der Rijst onder die skuilnaam Oom Willem met die titel Samesprake in Afrikaans en Engels met ' $n$ lys van woorde en uitdrukkings.

Van 1885 verskyn 'n paar boeke van die opvoedkundige, skrywer en digter Hubertus Elffers, wat van besondere leksikografiese betekenis is. In 1885 publiseer hy sy Practical Dutch grammar and analysis waarin 'n lys opgeneem is van "Cape idioms, with their Dutch and English equivalents". In 1895 verskyn The commercial Dutch grammar ook met 'n lys "Cape idioms" en in 1900 The Englishman's guide to the speedy and easy acquirement of Cape Dutch wat 'n hele paar woordelysies bevat met vroeë Kaaps-Hollandse of Afrikaanse materiaal (Elffers 1885: 298-326; 1895: 358-383; 1903: 20-96; SABW 1 1968: 286).

In 1885 het ook ' $n$ woordelys verskyn waarvan die samesteller onbekend is. Dit is Woordenlijst van het Transvaalsch taaleigen wat saam met ' $n$ inleidende Transvaalsche Spraakkunst in Onze volkstaal, tijdschrift gewijd aan de studie der $\mathrm{Ne}$ derlandsche tongvallen, onder redaksie van Taco $\mathrm{H}$. de Beer opgeneem is. Die lys is ' $n$ groot verbetering op dié van Tromp en is moontlik 'n uittreksel uit Mansvelt se werk. Dit is 'n uitsluitlik verklarende woordelys en is ook in Vroe $\ddot{e}$ Afrikaanse woordelyste opgeneem (Van der Merwe 1971: xi en 41).

'n Woordelys van ds. Willem Postma dateer uit 1896, maar verskyn eers in 1971 in druk in Vroe $\ddot{e}$ Afrikaanse woordelyste. Dit is destyds deur Postma aan S.J. du Toit gestuur in 'n prysvraag vir "suiwer gesmede" Afrikaanse woorde. Willem Postma het heelwat skryfwerk gelewer onder die skuilnaam Dr.

dr. F.J. Snijman, destydse Hoofredakteur van die WAT, besorg. Dit word tans by die Buro van die WAT in bewaring gehou. 
O'Kulis en was 'n seun van ds. Dirk Postma, die vader van die Gereformeerde Kerk in Suid-Afrika. Sy woordelys bevat veral materiaal uit Noord-Kaapland en die Oranje-Vrystaat (Van der Merwe 1971: xii en 53).

Ander vermeldenswaardige "vroeë woordelyste" wat ook deur H.J.J.M. van der Merwe in die inleiding tot sy heruitgawe van die Patriot-woordeboek (1968) vermeld word en deur G.S. Nienaber (1984) in sy bundel opgeneem is, is dié van D.U.M. (English and Cape-Dutch, 1872), H.A.L. Hamelberg (Het Nederlandsch in den Oranje-Vrijstaat, 1879), Baron F. van Hogendorp (in 'n bespreking van die genoemde boek van T.M. Tromp, 1879), adv. M.L. Wessels (Cape-Dutch, 1880), C. Stoffel (Eene wettige dochter der Hollandsche taal, 1882), J. te Winkel (Het Nederlandsch in Noord-Amerika on Zuid-Afrika, 1896 - hy het veral ontleen aan Changuion en Mansvelt se lyste), D.C. Hesseling (Het Hollandsch in Zuid-Afrika, 1897) en G.J. Boekenoogen (Afrikaansch en Noordhollandsch, 1903).

Die eerste Afrikaanse woordeboek, waarna reeds verwys is, se volledige titel was Patriot woordeboek/Patriot dictionary, Afrikaans-Engels/Cape Dutch-English, Engels-Afrikaans/English-Cape Dutch. Dit is in 1902 in die Paarl uitgegee deur D.F. du Toit en Co. In die "Foorberig" word onder andere gesê: "Wat ons gé is egter ni 'n uitfoerige woordeboek ni; ons het ons toegeleg op korthyd gepaard met folledighyd, om 'n handige sakwoordeboek te kry" (Boshoff 1926: 313; Patriot woordeboek 1902: III; Pienaar 1946: 205). Die woordeboekie behandel ongeveer 16500 woorde in die sogenaamde Patriot-spelling en het, anders as sy voorgangers, ' $n$ positief Afrikaanse grondslag en strekking (Snijman 1975: 6).

S.J. du Toit het hierdie leksikografiese werk later voortgesit met Afrikaanse taalskat, 'n verklarende lys van ongeveer 700 woorde wat strek van $A$ tot $F$ en wat tussen 1908 en 1909 gepubliseer is in die tydskrif Ons Taal, die opvolger van die eerste Afrikaanse tydskrif, Ons Klyntji. Ook hierdie lys is gepubliseer deur H.J.J.M. van der Merwe in Vroeë Afrikaanse woordelyste (Snijman 1975: 6).

Omstreeks 1900 het 'n paar leksikografiese werkies van vertalende aard verskyn wat bedoel was as hulp by die gebruik of aanleer van Afrikaans. In 1901 word in Londen en Edinburg $A$ handy vocabulary, English-Afrikander, Afrikander-English - for the use of English-speaking people in South Africa deur G.M.G. Hunt gepubliseer. Van Hunt is verder niks bekend nie, behalwe dat 'n tweede druk van sy boekie reeds in 1902 verskyn het. Dit was 'n goed versorgde werkie in die Patriot-spelling met opmerkings by sommige woorde. ' $n$ Ander boekie het in 1902 in Amsterdam en Kaapstad verskyn, naamlik An English-Cape Dutch vocabulary for the use of Englishmen deur J.F. van Oordt. Van Oordt was 'n skrywer wat sy vernaamste werke onder die skuilnaam D'Arbez geskryf het. Sy boekie is ' $n$ Engels-Afrikaanse woordelys van ongeveer 4800 woorde waarin die Patriot-spelling verruil word vir ' $n$ nouer aansluiting by Nederlands. 'n Ander werkie wat vermelding verdien, is die Afrikaans-Duitse Glossar wat opgeneem is in die Praktisches Lehrbuch der kapholländischen Sprache (Burensprache) deur N. Marais-Hoogenhout van Wellington wat sy doktorsgraad in die lettere in 1902 in Straatsburg behaal het. Dit bevat ongeveer 2300 Afrikaanse woorde 
in 'n eie spellingstelsel wat volgens die skrywer op die Afrikaanse klanksisteem gebaseer is (Snijman 1975: 6).

\section{Stryd tussen Afrikaans en Nederlands}

Ná die Tweede Vryheidsoorlog het 'n verbete stryd tussen Afrikaans en Nederlands ontwikkel. Die Tweede Afrikaanse Taalbeweging is ingelui met die stigting van die Afrikaanse Taalgenootskap (ATG) in die Noorde onder leiding van die skrywer Gustav Preller (1905) en die Afrikaanse Taalvereniging (ATV) in die Suide onder leiding van die skrywers J.H.H. de Waal en D.F. Malherbe, die latere Eerste Minister, D.F. Malan, en andere (1906) (Snijman 1975: 7). Die Nederlandsgesinde Z.A. Taalbond het in 1904 'n kongres in Kaapstad gehou waarop besluit is om die Vereenvoudigde Nederlandse Spelling (die sg. Kollewijn-spelling) in te voer en ook om voorsiening te maak vir die nodige woordeboeke in hierdie spelling. ' $n$ Gevolg van dié besluit was die verskyning in 1908 van die Beknopt Nederlands woordeboek voor Zuid-Afrika van Hubertus Elffers en dr. W.J. Viljoen, professor in moderne tale en geskiedenis aan die Victoria Kollege, Taalbondman en voorste kampvegter vir Nederlands. Dit is 'n lywige woordeboek met heelwat Afrikaanse woorde, aangedui as "Z.A.". Die werk is opgedra aan De Zuid-Afrikaanse Taalbond. In die lys van "Eerste Intekenaren" kom name voor soos J.B.M. Hertzog, J.C. Smuts, C.R. de Wet, M.T. Steyn, F.S. Malan en G.G. Cillié (Snijman 1963: 58; 1975: 7).

Van dieselfde skrywers het 'n paar maande later ook 'n vertalende woordeboek verskyn: English-Dutch and Dutch-English dictionary, eweneens in die Vereenvoudigde Spelling, wat volgens C.J. van Rijn "tans hier voorgoed [is] ingeburgerd". Van Rijn was 'n onderwyser van Kaapstad wat Nederlandse skoolboeke geskryf het en wat ongeveer dieselfde tyd as Elffers en Viljoen se vertalende woordeboek 'n woordeboek die lig laat sien het waarvan die volledige titel lui: Hollands-Engels en Engels-Hollands woordeboek voor Zuid-Afrika en Europa in de Vereenvoudigde (Kollewijn) Spelling, met de beste Kaapse woorden, met aanduiding in het tweede deel van de uitspraak van elke woord. Die "Kaapse" woorde word deur Van Rijn aangedui as "S.A." (Snijman 1963: 61-62).

\section{Bydrae van 'n Britse leraar}

Van betekenis vir die Afrikaanse leksikografie was eerw. Charles Pettman (wat in 1876 uit Engeland na Oos-Londen gekom het as die eerste leraar van die Metodiste-gemeente) se Africanderisms, a glossary of South African colloquial words and phrases and of place and other names wat in 1913 verskyn het. Hierdie werk is waardevol as aanduiding van die invloed van "Hollands" op Engels en dit het waarskynlik ook 'n rol gespeel by die verspreiding van Afrikaanse woorde, 
dikwels nog in 'n tipies Nederlandse gedaante, in die Engelse taal (Pettman 1913: iii; Snijman 1963: 69-70).

\section{Zuid-Afrikaanse Akademie voor Taal, Letteren en Kunst}

Die Zuid-Afrikaanse Akademie voor Taal, Letteren en Kunst het op 1 tot 2 Julie 1909 in Bloemfontein tot stand gekom. Deur dié liggaam is 'n versoening teweeggebring tussen die Nederlandsgesinde Taalbond en die Afrikaansgesinde ATV (Schumann 1959: 73-85). In 1914 het daar in die Jaarboek van die Akademie 'n ."Lijst van in Zuid-Afrika aangenomen en gangbare Hollandse ekwivalenten van Engelse woorden" verskyn "wat veral bestaan uit sport- en vliegterme wat deur die Akademie goedgekeur is (1959: 118; Snijman 1963: 73). Dit was van baie groot betekenis dat die Akademie na vore getree het as die instansie wat leiding gee ten opsigte van die reëling van die Afrikaanse spelling, Met dié stap is voldoen aan 'n belangrike voorvereiste vir werk op leksikogra. fiese terrein, want sonder 'n spellingreëling kon daar geen sprake wees van 'n algemeen aanvaarde woordeboek nie (Snijman 1963: 73).

Op die 1914-vergadering van die Akademie in Bloemfontein is ' $n$ "ontwerp-spelling" aan die vergadering voorgelê deur die taalkundige dr. T.H. le Roux. Die aangeleentheid is daarop verwys na ' $n$ kommissie wat bestaan het uit Le Roux, C.J. Langenhoven, J.D. du Toit (Totius), D.F. Malherbe, G.S. Preller, Jan F.E. Celliers en W.M.R. Malherbe. Die Spelreẻls wat deur dié kommissie opgestel is, is in 1915 gepubliseer en opdrag is gegee aan 'n nuwe kommissie, bestaande uit T.H. le Roux, D.F. Malherbe en J.J. Smith, om 'n Woordelys op te stel. Hierdie kommissie staan bekend as die Spellingkommissie of Woordelyskommissie (waaruit in 1929 die Taalkommissie ontstaan het) en die resultaat van hulle opdrag was die eerste Afrikaanse woordelijs en spelreëls wat in 1917 verskyn het (2de druk 1918, 3de hersiene druk 1921) (Le Roux 1926: 270-271; Schumann 1959: 118-120; Snijman 1963: 73).

\section{Tweetalige sakwoordeboeke}

Soos Afrikaans gaandeweg groter erkenning gekry en ' $n$ vaster vorm on twikkel het, het die leksikografiese behoeftes toegeneem. Daar was skielik 'n leksikografiese oplewing en in 1921 het verskillende tweetalige sakwoordeboeke feitlik gelyktydig verskyn. Die vertalende Woordeboek van M.S.B. Kritzinger (taalkundige en dosent aan die Transvaalse Universiteitskollege) en H.A. Steyn (onderwyser aan die Hoërskool Gimnasium, Potchefstroom), die Afrikaans-Engelse en Engels-Afrikaanse sakwoordeboek van P.A.M. Brink (jarelange skoolhoof asook burgemeester en sportadministrateur van Springs) en N.M. Hoogenhout (taalkundige, kultuur- en onderwysleier, seun van C.P. Hoogenhout, een van die stigters van die GRA) en die Afrikaanse woordeboekie van T. Kriel (waarskynlik 
Timo Kriel, bydraer tot Ons Moedertaal en 1914-rebel) het in die groot behoefte aan tweetalige woordeboeke probeer voorsien. Vier jaar later het die DuitsAfrikaanse, Afrikaans-Duitse Wörterbuch van H.A. Steyn, H.G. Schulze (later professor in Duits aan die PU vir CHO) en $\mathrm{H}$. Gutsche (predikant, opvoedkundige en komponis) verskyn (Snijman 1963: 76).

\section{Vak- en streektaal}

Dr. D.F. du Toit Malherbe, chemikus en een van die stigterslede van die ATV, se "vergelijkende woordelys van chemiese terme" wat reeds aan die begin van 1918 verskyn het, verdien ook vermelding. Dit is die Engels-Afrikaanse skeikundige terminologie (Bloemfontein), ' $n$ beskeie publikasie van 32 bladsye, maar van groot belang omdat dit waarskynlik die eerste vakwoordelysie in Afrikaans was. Dr. Malherbe het reeds in 1896 as skoolseun 'n lys van Afrikaanse woorde vir die Patriot woordeboek versamel en het later 'n baie waardevolle medewerker van die WAT geword (Snijman 1963: 76).

Die werk van G.R. von Wielligh, oud-Landmeter-generaal van die Z.A. Republiek en een van die laaste oorlewendes van die GRA, alhoewel nie leksikografies van aard nie, moet ook vermeld word, aangesien dit van groot belang was vir die leksikografie en vir die WAT in die besonder. Sy boek Ons Geselstaal (1925) bevat 'n kosbare skat aan volkstaal wat vir die WAT deur die jare 'n uiters waardevolle bron was. Prof. J.J. Smith het 'n groot rol gespeel in die bekendstelling en publikasie van Von Wielligh se werk en het ook die inleiding tot Ons Geselstaal geskryf (Snijman 1975: 13; Von Wielligh 1925: 9-10; WAT I 1950: vi).

Met hierdie vroeë woordelyste en woordeboeke is die grondslag van 'n leksikografiese tradisie in Suid-Afrika gelê. Teen 1926 was die Afrikaanse verklarende leksikografie egter nog ' $n$ onbekende en onverkende terrein.

\section{Verwysings}

Boshoff, S.P.E. 1926. 'n Standaardwoordeboek van Afrikaans. Gedenkboek tet ete oan die Genootskap tan Regte Afrikanets 1875-1925. Potchefstroom: Afrikaanse Studentebond.

De Kock, W.J. (Hoofred.). 1968. Suid-Afrikaanse biografiese woordeboek (SABW). Deel I. Kaapstad: Nasionale Boekhandel.

Elffers, H. 1885. Practical Dutch grammar and analysis. Kaapstad: Juta.

Elffers, H. 1895. The Commercial Dutch Grammar. Kaapstad, Johannesburg: Juta.

Elffers, H. 1903. The Englishman's Guide to the Speedy and Easy Acquirement of Cape Dutch. Kaapstad, Johannesburg: Juta.

Hunt, G.M.G. 1901. A Handy Vocabulary, English-Afrikander, Afrikander-English - for the Use of English-speaking People in South-Africa. Londen, Edinburg. Blackwood. 
Le Roux, T.H. 1926. Die geskiedenis van die Afrikaanse spelling. Gedenkboek ter ere zan die Genootskap van Regte Afrikaners 1875-1925. Potchefstroom: Afrikaanse Studentebond.

Mansvelt, N. 1884. Proeoe oan een Kaapsch-Hollandsch idioticon. Kaapstad, Stellenbosch: Cyrus ]. Martin.

Marais-Hoogenhout, N. s.j. Praktisches Lehrbuch der kaphollandischen Sprache (Burensprache). Wenen, Leipzig: Hartleben.

Nienaber, G.S. 1950. Taalkundige belangstelling in Afrikaans tot 1900. Johannesburg: Afrikaanse Pers-Boekhandel.

Nienaber, G.S. (Red.). 1984. Vroed opoattings oor Afrikaans as taal. Johannesburg Kaapstad: Perskor.

Patriot woordeboek/Patriot dictionary. 1902. Paarl: D.F. du Toit en Co.

Pettman, C. 1913. Africanderisms. Londen, New York: Longmans, Green and Co.

Pienaar, E.C. 1946. Die triomf oan Afrikaans. Kaapstad, Bloemfontein: Nasionale Pers.

Scholtz, J. du P. 1939. Die Afrikaner en sy taal, 1806-1875. Kaapstad: Nasionale Pers.

Schoonees, P.C. (Hoofred.). 1950. Woordeboek van die Afrikaanse Taal. Deel I. Pretoria: Staatsdrukker.

Schumann, T.E.W. et al (Red.). 1959. Feesalbum 1909-1959 (van die Suid-Afrikaanse Akademie vir Wetenskap en Kuns). Pretoria: J.L. van Schaik.

Snijman, F.J. 1963. Die Afrikaanse Woordeboek teen sy agtergrond. Ongepubliseerde studie.

Snijman, F.J. 1975. $U$ woorde, $u$ woordeboek. Stellenbosch: Beheerraad van die Woordeboek van die Afrikaanse Taal.

Van der Merwe, H.J.J.M. (Réd.). 1968. Patriot-woordeboek (heruitga we). Pretoria: J.L. van Schaik.

Van der Merwe, H.J.J.M. (Red.). 1971. Vroed Afrikanse woordelyste. Pretoria: J.L. van Schaik.

Van Oordt, J.F. 1902. An English-Cape Dutch Vocabulary for the Use of Englishmen. Amsterdam, Kaapstad: H.A.U.M.

Von Wielligh, G.R. 1925. Ons geselstaal. Pretoria: J.L. van Schaik. 